\title{
WORKPLACE FOR MEASURING MAGNETIZATION CHARACTERISTICS OF MICROWIRE SENSORS
}

\author{
Martin FILKO*, Pavol LIPOVSKÝ, Václav MOUCHA, Jozef HUDÁK, Jozef NOVOTŇÁK \\ Technical university of Košice, Faculty of Aeronautics, Rampová 7, 04121 Košice, Slovak republic \\ *Corresponding author. E-mail: martin.filko@tuke.sk
}

\begin{abstract}
Microwires can be used for different purposes and one of them is magnetic field measurement. In order to better understand the behavior of the microwires when measuring the magnetic field it is necessary to know their magnetization characteristics. This article is description workplace for measuring magnetization characteristics of microwire sensors, which was carried out at the Department of Aviation Technical Preparation of the Faculty of Aeronautic.
\end{abstract}

Keywords: microwire; workplace; magnetization; measuring; windings; coil

\section{INTRODUCTION}

Magnetic microwires have found their application in sensor manufacturing and other applications where their specific magnetic properties are exploited. The microwires are characterized by a domain structure that externally exhibits bistable magnetic behavior, i.e. a perfectly rectangular hysteresis loop. Such a pre-magnetizing process makes magnetic microwires the ideal materials for use in a variety of applications in different areas [1].

In order to better know the behavior of the microwire in the magnetic field, it is necessary to know its magnetization characteristics. In order to determine the magnetization characteristics of the microwires, we have created a measuring workplace. In this article, we will describe the individual components and devices used to build the workplace.

\section{MEASUREMENT DEVICE}

This simple measuring workplace is designed to measure the magnetization characteristics of microwire sensors. The workplace consists of a signal generator, an oscilloscope and the measuring coil itself. The magnetic properties of the measured magnetic microwire can be determined with this measuring coil. The measuring coil consist of four windings that can be used to create excitation magnetic fields or for sensing of the magnetic field signal. The coil was designed in such way that it has small dimension but it is capable to create magnetic fields with sufficient magnitude.

The magnetic characteristic measurement device consist from two parts (figure 1). The base part is measuring coil. The coil is fixed in the holder made with additive 3D printing (figure 2), precisely made for the measuring coil (designed in Creo Parametric, printer Prusa i3 plus). The device also includes terminals for convenient wiring connection [2]. 


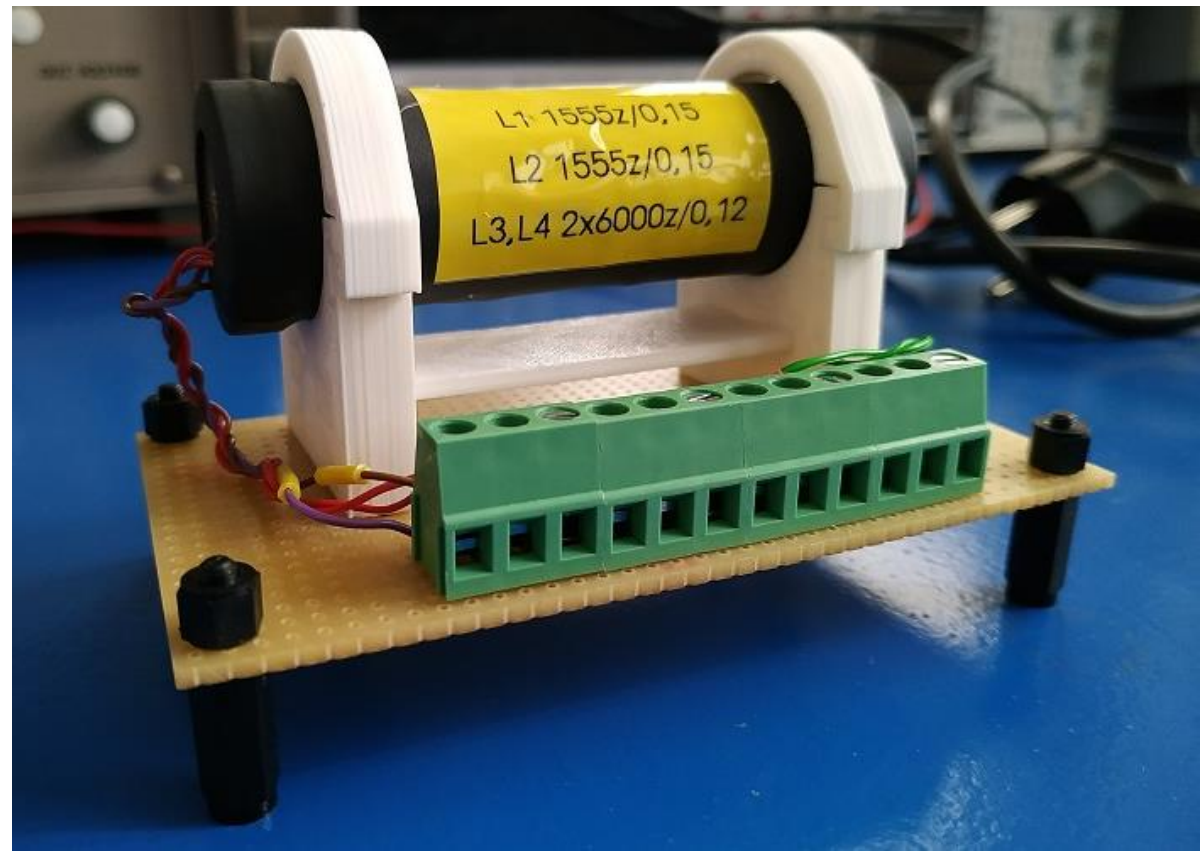

Figure 1 Measurement device

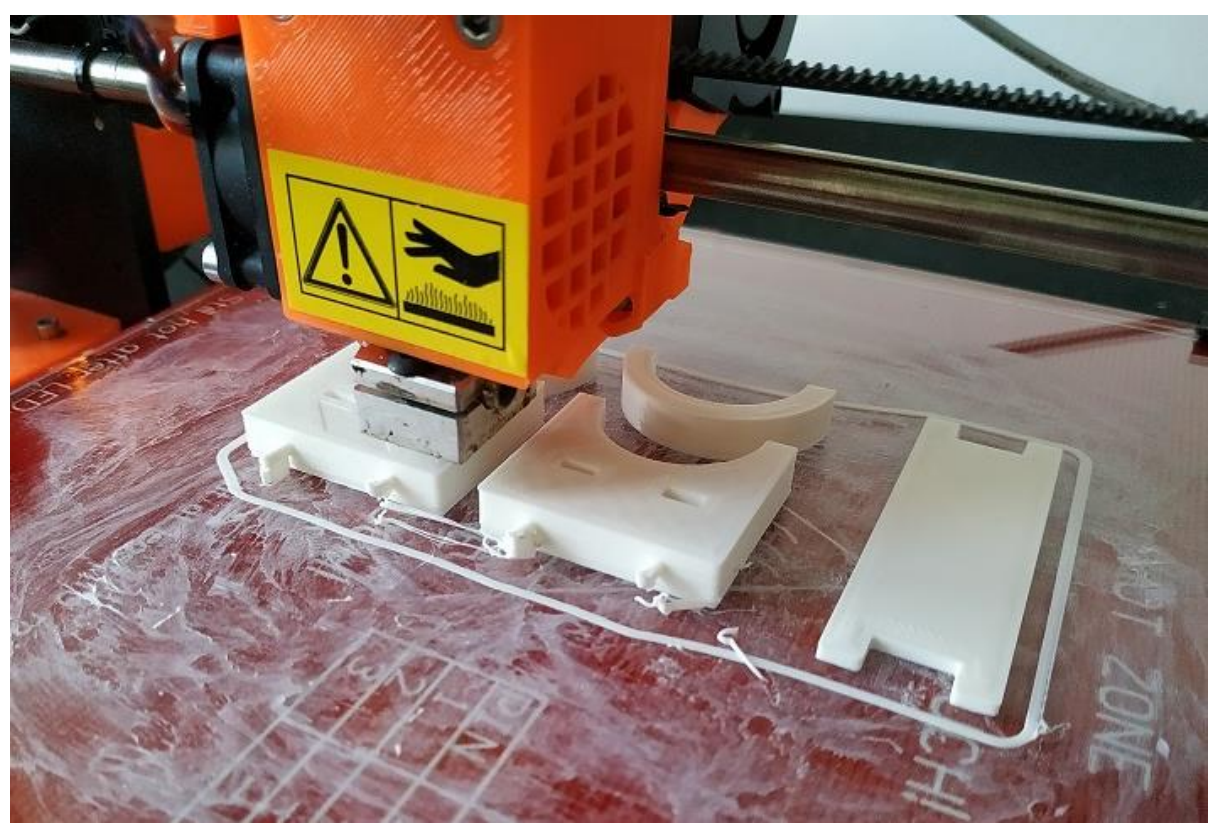

Figure 2 3D printing holder

The magnetic coil has two excitation windings wound along the whole lengths of the coil (air core). Each of the windings is wound with the wire diameter $0.12 \mathrm{~mm}$ in 6000 turns, designated L1 and L2. The excitations windings can work separately or can be connected in series to achieve magnetic field with approximately doubled magnitude. These two windings can be also used as a linear transformer.

The sensing windings designated LA and LB are placed in $15 \mathrm{~mm}$ distance from the coil ends. There is a $30 \mathrm{~mm}$ space between these sensing windings to minimize mutual influence (interference). The sensing windings are made from copper core with $0.15 \mathrm{~mm}$ diameter in 1555 turns (figure 3 ). 


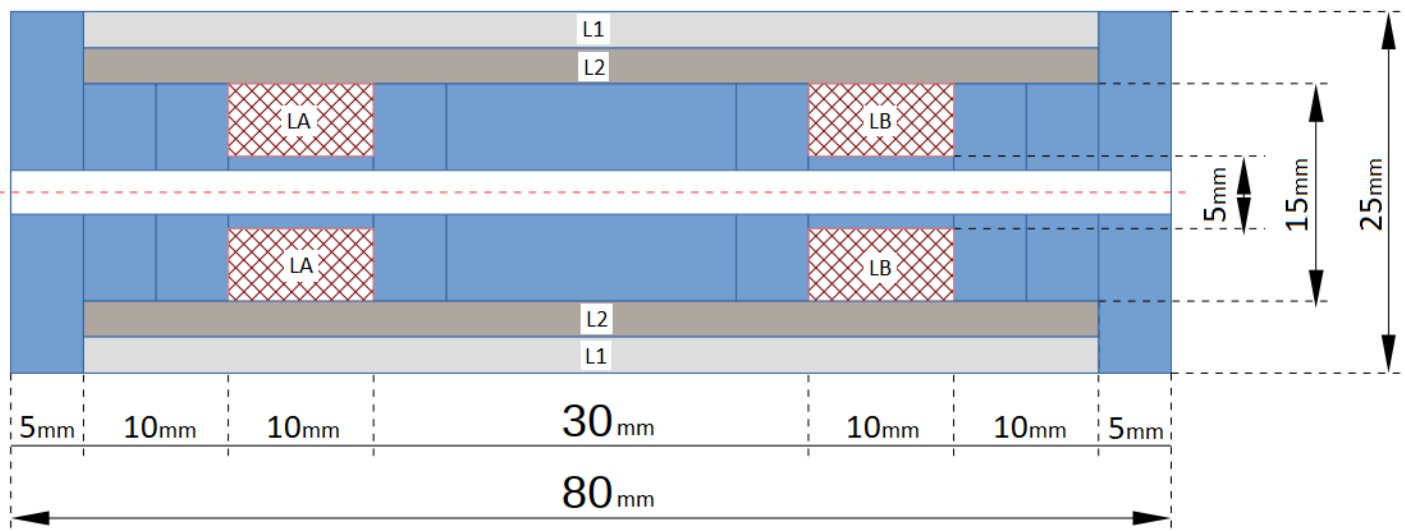

Figure 3 Measuring coil

These two windings can suppress external interference from the environment - during the measurement the magnetic material core (microwire or small thin ribbon) is placed inside one sensing coil, e.g. LB, whereas the second sensing winding (LA) is without core. If these two winding are connected in series in opposite direction, both of the windings are influenced by the excitation field and also environment magnetic field. Since the sensing windings are connected in opposite series, the induced voltage has the same magnitude in both windings but in opposite phase, thus they cancel out. In such way the environment interference is suppressed and the measurer signal is clearer.

In order to verify the functionality of the measuring coil, we measured the inductance and the resistance of the coil winding, which are the basic parameters of the measuring coil. Inductance and resistance were measured using a precision device LCR 816 , which allows us to measure inductance in the range of $0.01 \mathrm{pH}$ to $100 \mathrm{kH}$ and resistance in the range of $0.01 \mathrm{~m} \Omega$ to $100 \mathrm{M} \Omega$ and measuring resistance realized digital multimeter UT70B. Based on the test frequency, it can also verify quality factor $[3,4]$.

The basic physical quantity at the coil is the inductance (measured in henry units), which depends on the coil dimensions, the number of turns and the permeability of the core. Due to the final conductivity of the conductor from which the coil is made, it also has a resistor that is replaced by a series resistor in the calculations [3].

Inductance measurement and resistance measurements were realized at $100 \mathrm{~Hz}$. Own but also mutual inductance as well as resistance of individual coil windings were measured.

Table 1 Inductance and Resistance

\begin{tabular}{|c|c|c|c|c|c|}
\hline $\begin{array}{c}\text { Name } \\
\text { Windings }\end{array}$ & $\begin{array}{c}\text { Inductance L } \\
{[\mathrm{mH}]}\end{array}$ & $\begin{array}{c}\text { Inductance } \\
\text { Quality } \\
\text { Factor Q }\end{array}$ & $\begin{array}{c}\text { Resistance R } \\
{[\Omega]}\end{array}$ & $\begin{array}{c}\text { Resistance } \\
\text { Quality Factor } \\
\mathrm{Q}\end{array}$ & $\begin{array}{c}\text { Resistance R } \\
\text { UT70B } \\
{[\Omega]}\end{array}$ \\
\hline L1 & 137,68 & 0,1660 & 521,37 & 0,1641 & 522 \\
\hline L2 & 136,88 & 0,1671 & 515,43 & 0,1669 & 516 \\
\hline LA & 14,16 & 0,2038 & 43,64 & 0,2063 & 44,1 \\
\hline LB & 14,68 & 0,2092 & 44,04 & 0,2125 & 44,5 \\
\hline
\end{tabular}


Table 2 Mutual inductance

\begin{tabular}{|c|c|}
\hline Mutual inductance L1 a L2 & $\begin{array}{c}\text { Inductance L } \\
{[\mathrm{mH}]}\end{array}$ \\
\hline Windings connected in series in the same direction & 524 \\
\hline Windings connected in series in opposite direction & 125,5 \\
\hline
\end{tabular}

\section{BLOCK STRUCTURE OF MEASURING WORKPLACE}

In this chapter we will describe the block structure of the measuring workplace. This workplace consists of 4 blocks. The first block of this block structure is a signal generator, in which we will generate the signal needed to excite the magnetic field in the field winding. Further, there is the measuring coil itself. The output of the sensing winding is applied to an analog-to-digital converter input where the signal is converted to digital and sent for further processing to a computer or processed in microcontroller. Instead of the AD converter / microcontroller block, we decided to use the DAQ (Data Acquisition) system Labjack T series, which with its versatile use and the ability to create its own software measurement environment, offers the ideal basis for our measurements. The use of labjack has many other advantages. For example, it has a 16-bit analog-to-digital converter that can use up to $200 \mathrm{kHz}$ sampling frequency in one channel. The measured data is then sent and processed by a computer [5].

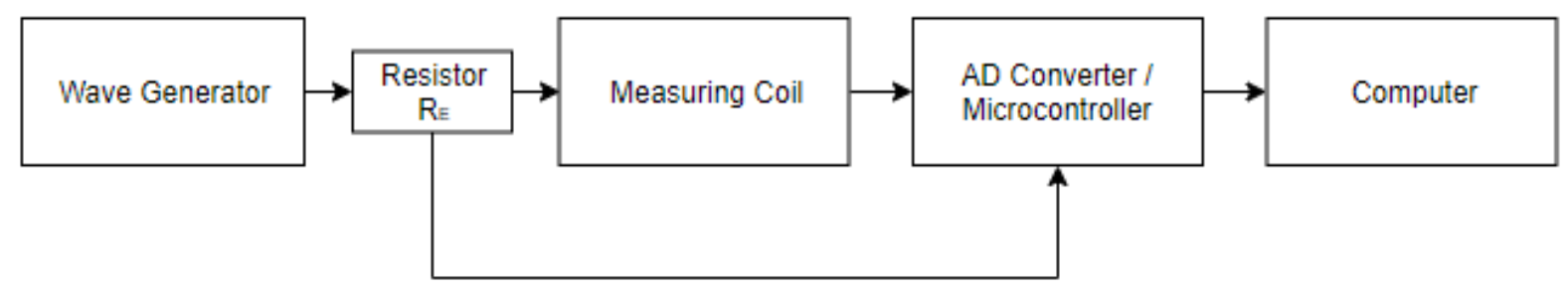

Figure 4 Block structure of measuring workplace

From the measured data we can then evaluate the individual magnetization characteristics of the microwires, namely the curve of primary magnetization and $\mathrm{BH}$ characteristics. In order to measure these parameters, we need to know the voltage, current and impedance transmissions [6].

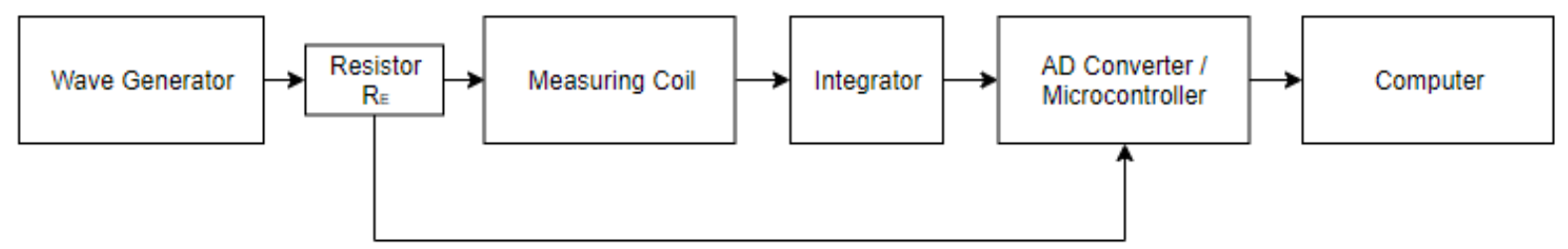

Figure 5 Block structure of measuring workplace with integrator

When measuring the $\mathrm{BH}$ characteristics, it is necessary to introduce the integration of the output voltage from sensing windings of measuring coil that carries information about size B (magnetic induction). The size $\mathrm{H}$ (magnetic field strength) information is then obtained by measuring the current flowing through excitation winding [6]. 


\section{CONCLUSION}

This document describes a workplace for measuring the magnetization characteristics of microswires. There are described the individual components and devices that were used to build the workplace. The second chapter describes the measuring coil in terms of construction and functionality. In the third chapter we showed the block structure of the workplace and described the individual blocks.

Further work at this measuring workplace would be to verify the functionality of the measurement coil and the entire measurement chain. It is necessary to measure and verify the properties of the measuring coil without the core. Then will be design software to process the measured data.

\section{ACKNOWLEDGEMENT}

This work was supported by the KEGA No. 052TUKE-4/2018, KEGA No. 058TUKE-4/2018, VEGA No. 1/0374/17, APVV-17-0184 and APVV-16-0079 projects. The authors would like to thank the project management and colleagues for support and valuable questions, remarks and suggestions.

\section{References}

[1] Magnetic Microwire. Košice: Faculty of Aeronautics. 2009. Available at: http://senzorika. Letecka fakulta.sk/?q=node/164

[2] 3D printing. How Does 3D Printing Work. Available at: https://3dprinting.com/what-is-3dprinting/

[3] Elektrické meranie, Meranie indukčnosti, Ing. Alexander szanyi Available at: http://cloud6.edu page.org/cloud/Meranie_indukcnosti.pdf?z\%3A\%2B9G\%2BhJ2c\%2BEVhiiW\%2BbSPNKR EaaCdmKdPkVrLax9XEdPHQQNAYCveLfx1E7E0huTMZ

[4] Datasheet Gwinstek, Available at: https://www.csulb.edu/sites/default/files/groups/college-of-engi neering/About/gwinstek_lcr_meter.pdf

[5] LabJack T series. datasheet . Available at: https://labjack.com/products/t7

[6] Colonel Wm. T. McLyman. Magnetic Materials and Their Characteristics, Transformer and Inductor Design Handbook. Third Edition, Revised and Expanded Idyllwild, California, USA: Kg magnetic, Inc. 2004. 50-52p.

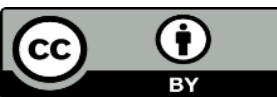

Article is licensed under a Creative Commons Attribution 4.0 International License 